Available online at GSC Online Press Directory

GSC Biological and Pharmaceutical Sciences

e-ISSN: 2581-3250, CODEN (USA): GBPSC2

Journal homepage: https://www.gsconlinepress.com/journals/gscbps

(RESEARCH ARTICLE)

\title{
Biochemical studies on the antidiabetic properties of immature palmyra palm fruits studied in high fat diet fed-low dose streptozotocin induced type 2 diabetes in rats
}

\author{
Krishnamoorthy Renuka, Neeli Parvathi and Sorimuthu Pillai Subramanian * \\ Department of Biochemistry, University of Madras, Guindy Campus, Chennai- 600025.
}

Publication history: Received on 19 September 2020; revised on 29 September 2020; accepted on 30 September 2020

Article DOI: https://doi.org/10.30574/gscbps.2020.12.3.0304

\begin{abstract}
Borassus flabellifer Linn. commonly known as the "Palm tree" is a tall, erect and celestial tree with more than 800 established uses. The immature palmyra palm fruits have been traditionally used for the treatment of diabetes and its secondary complications. In the absence of systemic reports in the literature, the present study was aimed to evaluate the antidiabetic and antioxidant properties of the immature fruits in High fat diet-fed low-dose STZ induced experimental type 2 diabetes in rats. Diabetic rats were orally treated with palmyra palm fruits extract at a concentration of $400 \mathrm{mg} / \mathrm{kg}$ b.w. for 30 days. Oral glucose tolerance test was performed. The levels of fasting blood glucose, plasma insulin, HbA1c, HOMA-IR values were estimated. The activities of key enzymes involved in carbohydrate and glycogen metabolism in the liver and kidney tissues were assayed. The glycogen content in liver tissue was estimated. Chemical analysis evidenced the presence of pharmacologically important phytochemicals and the significant levels of phenolic and flavonoid content in the fruit extract. The alterations observed in the diabetic rats on the important biochemical indices such as fasting blood glucose, insulin, hemoglobulin, and glycosylated hemoglobulin were reverted to the physiological range after oral treatment with fruits extract. Likewise, the altered levels of protein, urea, uric acid and creatinine were normalized after treatment with fruits extract. The assay of activities of regulatory enzymes revealed the role of fruits extract in the regulation of carbohydrate and glycogen metabolism. The results of the present study provide substantial evidence for the rationale and antidiabetic properties of immature palmyra palm fruits extract.
\end{abstract}

Keywords: Palm tree; Immature palm fruits; Antidiabetic; Biochemical markers and Regulatory enzymes

\section{Introduction}

Diabetes mellitus (DM) is a polygenic metabolic disorder that arises due to deficiency (T1DM) and/ or efficiency (T2DM) of insulin [1]. It is characterized by a chronic elevation in the levels of fasting, post prandial, random and glycosylated hemoglobin. The incidence of diabetes is increasing alarmingly worldwide due to genetic and environmental factors [2,3]. Though, T1DM and T2DM have the same long-term complications, the former is known to elicit more severe complications. T2DM accounts for more than $90 \%$ of the total diabetic population. Chronic hyperglycemia in diabetes is the third uppermost risk factor for the development of micro as well as macrovascular complications and premature mortality $[4,5]$. Impairment of carbohydrate, fat and protein metabolism and chronic hyperglycemia induced oxidative stress are the life- threatening consequences of DM [6]. The currently available drugs for the treatment of DM include insulin injections and oral antidiabetic drugs having a different mechanisms of actions such as stimulation of insulin secretion, enhance the insulin sensitivity, decrease insulin resistance, control the processes of gluconeogenesis, glycogenesis and interfere with the absorption of nutrients in the intestine [7]. These oral antidiabetic drugs are prescribed either as monotherapy or in combination to achieve better glycemic control and

${ }^{*}$ Corresponding author: Sorimuthu Pillai Subramanian

Department of Biochemistry, University of Madras, Guindy Campus, Chennai- $600025 .$.

Copyright $(2020$ Author(s) retain the copyright of this article. This article is published under the terms of the Creative Commons Attribution Liscense 4.0. 
insulin treatment remains the corner stone for the treatment of both T1DM and T2DM. However, no ideal therapy is still available to control chronic hyperglycemia due to the development of undesirable side effects and diminution after prolonged use. Hence the search for newer drugs preferably from plant origin with better efficacy and without long term side effects continues.

Throughout the world, several medicinal plants have been found successful for the treatment of numerous primary and secondary health complications and their demand is increasing exponentially due to the growing recognition of natural products, being non-toxic, more efficacies and easily available at an affordable price. The ecologically derived secondary metabolites produced by the plants serve as the priceless chemical library for drug discovery in the pharmaceutical industry. In fact, more than $60 \%$ of the marketed medicines are distillations, combinations, reproductions or variations of substances that exist in nature [8]. Our ancestors recommended some of the natural products, which are profusely found in nature long before their medicinal values were established and attested by scientific validation.

However, few natural products have received toxicological as well as medical scrutiny for their pharmaceutical applications. The World Health Organization has consistently insisted that the traditional medicinal plant treatments warrant systematic evaluation for their toxicity and efficacy. Palmyra palm is commonly known as "Palm tree" and is one such medicinal plant that has not been subjected to systemic scientific scrutiny for the therapeutic applications of its various parts.

Borassus flabellifer Linn ("Arecaceae") is a tall and erect tree widely known for its large, fan-shaped leaves [9]. India stands first in the world in terms of its possession with a population of more than 125 million [10] and out of this nearly $60 \%$ are in Tamil Nadu [11]. It is commonly referred to as the "tree of life" with more than 800 established uses including food, beverage, fiber, medicinal and timber [12]. In the highly esteemed antiquity Tamil culture, it is considered as "Karpaha Veruksham" (Celestial tree) because all its parts have a unique use [13]. Above all, due to the special contemporary significance, this tree is pronounced as the official tree of Tamil Nadu in 1978 [14]. In traditional medicine, the extract of immature palm fruits has been widely used for the treatment of diabetes and its secondary complications $[15,16]$. Recently, we have reported the antioxidant and antimicrobial properties of immature palm fruits $[17,18]$. In the present study, it was aimed to evaluate the antidiabetic properties of immature fruits in High Fat Diet fed and Low Dose Streptozotocin induced experimental type 2 diabetes in rats.

\section{Material and methods}

\subsection{Chemicals and drugs}

Streptozotocin (STZ) was procured from Sigma Chemicals, St Louis, USA. All other chemicals and reagents used in the present study were of analytical grade obtained from SRL chemicals, Bombay, India.

\subsection{Plant material}

The immature Palmyra palm fruits (prior to the development of endosperms) that have weighed between 30 to 50 gm were collected from the trees near Chengalpet, Tamil Nadu during the months of December and January. The plant material was authenticated by a qualified taxonomist at the Centre for Advanced Studies in Botany, University of Madras and a voucher specimen was deposited for future reference.

\subsection{Preparation of the fruits extract}

The immature fruits were washed thoroughly under tap water and then rinsed in distilled water. The fruits were cut into thin slices and dried in an electric oven and powdered in mechanical grinder which was stored in an airtight container at $5^{\circ} \mathrm{C}$ until further use. The powdered fruits were subjected to delipidation using petroleum ether $\left(60-80^{\circ} \mathrm{C}\right)$ overnight to selectively remove the lipids. The delipidated fruits extract was subjected to soxhalation using ethanol. The ethanolic extract of the fruits was filtered, dried and weighed and the yield was around $26 \%$.

\subsection{Phytochemical screening}

The ethanolic extract of immature palm fruits was subjected to phytochemical screening such as alkaloids, flavonoids, glycosides, saponins, tannins, phytosterols, triterpenoids, anthraquinones and phenols [19,20]. The experiments were conducted in triplicates to validate the data obtained. 


\subsection{Toxicity and dosage fixation studies}

The acute toxicity of immature palm fruits extract was studied in control rats according to OECD guideline 423 [21]. Graded doses of fruits extract was dissolved in water and administered orally and the animals were observed continuously for the first 2 hours followed by every hour up to 6 hours and daily thereafter for fourteen days for any signs of morbidity, mortality and behavioral changes. Similarly based on the reports available in the literature, graded doses of immature palm fruits $(100,200,300,400,500 \mathrm{mg} / \mathrm{kg}$ b.w.) were administered to HFD - low dose STZ induced diabetic rats for various periods of treatment [22]. From the data obtained, the optimum dosage was fixed as $400 \mathrm{mg} / \mathrm{kg}$ b.w. for 30 days.

\subsection{Experimental animals}

Male Wistar rats weighing about 160-180 g, procured from Tamilnadu Veterinary and Animal Sciences University, Chennai, India, were housed in clean, sterile, polypropylene cages $(38 \times 23 \times 15 \mathrm{~cm})$ under standard vivarium conditions. The animals were allowed free access to standard rat chow diet (Hindustan Lever Ltd., India) or high fat diet as the case may be and water adlibitum. The composition of the standard rat diet includes 5\% fat, 21\% protein, 55\% nitrogen-free extract and $4 \%$ fiber $(\mathrm{w} / \mathrm{w})$ with adequate minerals and vitamins for the animals. The animals were acclimatized to the laboratory conditions for two weeks before the commencement of experiments. The animal experiments were designed and conducted in accordance with the current ethical norms approved by Ministry of Social Justices and Empowerment, Government of India and Institutional Animal Ethical Committee Approval (IAEC No.04/01/2014).

\subsection{High fat diet fed - low dose streptozotocin induced diabetes}

The rats were divided into two dietary regimens either by feeding normal or high fat diet for two weeks [23]. After two weeks of dietary manipulation, the groups of rats fed with HFD were injected intraperitoneally with a low dose of STZ (35 mg/kg b.w) dissolved in 0.1M ice cold citrate buffer, pH 4.5. One week after STZ injection, the rats were analyzed for fasting blood glucose levels. The rats with fasting blood glucose (FBG) $>250 \mathrm{mg} / \mathrm{dl}$ that exhibited random hyperglycemia and glycosuria were chosen for further studies. The rats were allowed to continue to feed on their respective diets until the end of the experiments.

\subsection{Experimental Protocol}

The animals were divided into four groups, comprising a minimum of six animals in each group as follows:

Group 1 - $\quad$ Control rats.

Group 2 - $\quad$ HFD+STZ (i.p. 35mg/kg b.w.) induced diabetic rats.

Group 3 - $\quad$ Diabetic rats treated with immature palmyra palm fruits extract (400 mg/kg b.w./day) orally for 30 days.

Group 4 - $\quad$ Diabetic rats treated with metformin (200 mg/ kg b.w./day) in aqueous solution orally for 30 days.

During the experimental period, food and fluid consumption were recorded at regular intervals. At the end of the treatment period, the rats were fasted overnight, anesthetized and sacrificed by cervical decapitation. The blood was collected with and without anticoagulants for the separation of plasma and serum respectively.

\subsection{Oral glucose tolerance test (OGTT)}

Overnight fasted rats of all groups were subjected to oral glucose tolerance test on the last day of the experimental period. The blood glucose levels were monitored at 0, 30, 60, 90 and 120 min. using One Touch glucometer (Life scan, Johnson and Johnson Company) after oral administration of $2 \mathrm{~g} / \mathrm{kg}$ b.w. glucose as aqueous solution. The insulin resistance developed in the experimental animals was evaluated by a homeostasis model of insulin resistance (HOMAIR) [24]. The HOMA-IR was calculated using the formula.

HOMA-IR= Fasting insulin level $(\mu \mathrm{U} / \mathrm{mL}) \times$ Fasting blood glucose $(\mathrm{mg} / \mathrm{dl}) / 405$ 


\subsubsection{Biochemical parameters}

Blood glucose concentration was measured by the glucose oxidase method [25]. Plasma insulin and C-peptide were assayed using an ELISA kit for rats (Linco Research, Inc., USA). The levels of hemoglobin and glycosylated hemoglobin were estimated according to methods of Drabkin and Austin (1932) [26] and Nayak and Pattabiraman (1981) [27], respectively. Urine strips were used for the detection of sugar in the urine. Plasma protein and blood urea contents were determined by the method of Lowry et al., (1951) [28] and Natelson et al. (1951) [29] respectively. Serum creatinine and uric acid levels were determined by the method of Brod and Sirota, (1948) [30] and Caraway (1963) [31] respectively. The activity of Aspartate transaminase (AST), Alanine transaminase (ALT) and Alkaline phosphatase (ALP) were assayed by the method of King $(1965(a, b))[32,33]$.

\subsection{Assay of key enzymes of carbohydrate metabolism}

The liver tissue homogenate was centrifuged at 10,000 rpm to remove the debris and the supernatant was used as the enzyme source for the assay of hexokinase [34], pyruvate kinase [35], glucose-6-phosphatase [36], fructose-1, 6bisphosphatase [37], glucose-6-phosphate dehydrogenase[38], glycogen synthase [39] and glycogen phosphorylase [40]. Another portion of wet liver tissue was used for the estimation of glycogen content [41].

\subsection{Statistical analysis}

All the data obtained were grouped and statistically evaluated with the aid of SPSS 16.0 software. Hypothesis testing methods included 'One-way analysis of variance' followed by 'least significant difference test' was used. A value of P < 0.05 was considered to indicate statistical significance. All results were expressed as mean \pm Standard error mean (S.E.M) for six rats in each group.

\section{Results and discussion}

Phytochemical screening shows the presence of biologically active phytochemicals such as alkaloids, flavonoids, glycosides, saponins, tannins, phytosterols, and phenols in the immature Palmyra palm fruits extract. Phytochemicals are ecologically derived non-nutrient bioactive compounds produced by the plants to protect them from environmental stress such as drought, extreme cold and pathogenic microbes. Interestingly, the phytochemicals possess the ability to exert pharmacological as well as several beneficial effects on human health. The preliminary phytochemical screening forms the source for the quantitative estimation, extraction and identification of bioactive constituents present in various parts of medicinal plants. The qualitative analysis of the fruits extract evidenced that the immature fruits contain most of the imperative bioactive principles which readily accounts for its folklore medicinal claims. The results obtained are in accordance with the earlier reports on palm mesosperms [42, 43].

The total phenolic and flavonoid contents in the fruits extract and were found to be $104.00 \pm 0.02 \mu \mathrm{g}$ gallic acid equivalents $/ 100 \mathrm{mg}$ of fruits extract and $98.45 \pm 0.03 \mu \mathrm{g}$ quercetin equivalents/100mg of fruits extract, respectively. Phenols are considered as vital plant constituents because of their free radicals scavenging ability which in turn due to the presence of one or more hydroxyl groups in them [44]. Similarly, flavonoids are an important group of polyphenols widely distributed among the plant flora and containing a benzopyrone that is used as antioxidants or free radicals scavengers [45]. The significant levels of total phenolic and flavonoid contents provide further evidence for the presence of biologically active phytoingredients in the ethanolic extract of immature palm fruits [17].

The results of the toxicity and dosage fixation studies revealed that the fruits extract is non-toxic up to $2 \mathrm{~g} / \mathrm{kg}$ b.w. and the fruit extract showed dose-dependent hypoglycemic activity in HFD-STZ diabetic rats. Based on the results obtained, the optimum dosage was fixed as $400 \mathrm{mg} / \mathrm{kg} / \mathrm{b} . \mathrm{w} / \mathrm{rat} /$ day for 30 days. The changes in body weight in control and experimental groups of rats are shown in Figure 1. Diabetic group of rats showed a significant reduction in body weight when compared with the control group of rats. There was a significant improvement in body weight in diabetic rats after oral administration of immature palm fruits extract as well as metformin for 30 days. Induction of diabetes with HFD-STZ is associated with the characteristic loss of body weight, which is due to increased muscle wasting and catabolism of tissue proteins, which was also observed in the present study [46]. The improvement in the body weight observed in diabetic group of rats treated with the fruits extract indicates the maintenance of glucose homeostasis by controlling the muscle wasting. 


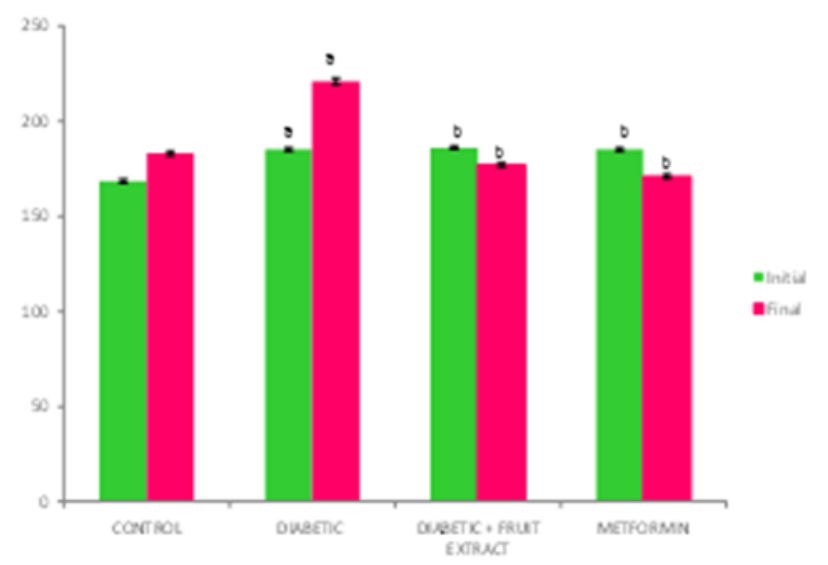

Results are expressed as mean \pm SEM $[n=6]$. One-way ANOVAfolloned by post hoc test LSD nas done. Whas are statistically siznificart at $\mathrm{p}<0.05$. The resuls were compared to catrol rats and compared to dibetic rats.

Figure 1 Effect of immature palm fruits extract on body weight gain in experimental groups of rats

Figure 2 shows the blood glucose levels of control and experimental groups of rats after an oral glucose load. After the oral glucose load, blood glucose levels peaked at $60 \mathrm{~min}$ and then gradually declined to near physiological levels at 120 min indicating the maintenance of normoglycemia in control group of rats, whereas, in the case of STZ-induced experimental type 2 diabetic group of rats, the peak increase in blood glucose concentration was observed after 60 min and remained high over the next $60 \mathrm{~min}$. Oral administration of fruits extract to HFD-STZ induced diabetic rats showed a statistically significant decrease in blood glucose concentration at 60 and 120 min indicating its blood glucose lowering efficacy which in turn may be due to the insulin stimulatory or insulin mimetic properties of the fruits extract and the efficacy was comparable with metformin. The oral glucose tolerance test (OGTT) is an established measure of effective glucose utilization by the system that generally aids in the early diagnosis of diabetes [47]. Impaired glucose tolerance (IGT) due to pancreatic dysfunction results in the defective utilization of glucose by the tissues and increased hepatic gluconeogenesis.

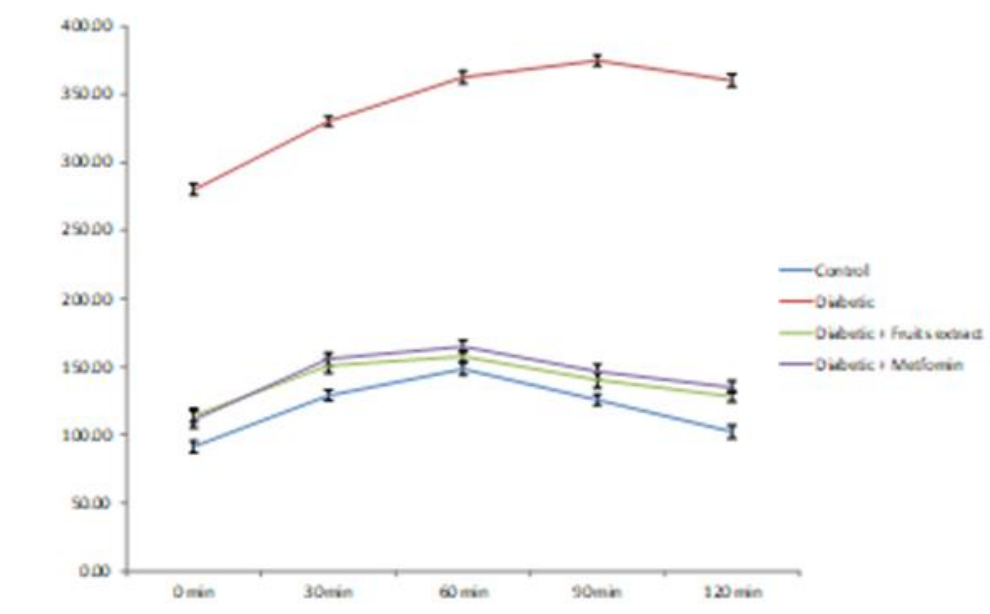

Result are expressed as mean $=$ SEM $[n=6]$. One-tway ANCWA followed by post hoc test LSD was done Vahes are statistically sigrificant at 'p<0.05. The sesults wese "compared to control rats and "compased to dibetic ats

Figure 2 The Effect of immature palm fruits extract treatment on OGTT in experimental groups of rats 
Table 1 shows the levels of blood glucose, glycosylated hemoglobin, plasma insulin and the presence of urine sugar in control and experimental groups of rats. The elevated levels of fasting blood glucose levels observed in the diabetic group of rats may primarily due to the excessive release of glucose from the liver by gluconeogenesis and glycogenolysis. Liver plays an essential role in the maintenance of normal blood glucose levels and is the primary organ responsible for endogenous glucose production. In fasting conditions, the liver produces glucose whereas, in the postprandial state, it stores excess glucose in the form of glycogen [48]. Insulin chiefly controls hepatic glucose production by regulating the key enzymes involved in gluconeogenesis and glycogen metabolism [49]. Dysregulation of carbohydrate metabolizing enzymes in diabetes due to insulin deficiency and/or its resistance increase the hepatic glucose production and decrease the storage of glucose as glycogen [50- 52]. The increased levels of glucose, glycosylated hemoglobin and decreased plasma insulin level in experimental diabetic rats were restored to near normal levels in fruits extract as well as metformin treated diabetic rats. The observed increase in insulin level along with decreased levels of glycosylated hemoglobin in fruits extract treated diabetic rats, evidenced that the treatment with fruits extract improved the pancreatic $\beta$-cell mass and function. Urine sugar present in diabetic rats was absent in palm fruits treated diabetic rats indicating the renoprotective nature of the fruits extract [53].

Table 1 Effect of oral treatment of immature palm fruits extract on the levels of fasting blood glucose, hemoglobin, glycosylated hemoglobin, plasma insulin and urine sugar in experimental groups of rats after 30 days of experimental period.

\begin{tabular}{|c|c|c|c|c|c|}
\hline Groups & $\begin{array}{l}\text { Fasting } \quad \text { Blood } \\
\text { Glucose }(\mathrm{mg} / \mathrm{dl})\end{array}$ & $\begin{array}{l}\text { HbA1c } \\
(\% \mathrm{Hb})\end{array}$ & Hemoglobin (\%) & $\begin{array}{l}\text { Plasma Insulin } \\
(\mu \mathrm{U} / \mathrm{ml})\end{array}$ & Urine sugar \\
\hline Control & $90.26 \pm 4.55$ & $6.59 \pm 0.45$ & $13.41 \pm 0.55$ & $14.68 \pm 1.45$ & Nil \\
\hline Diabetic & $267.65 \pm 21.63 \mathrm{a}^{*}$ & $12.60 \pm 1.89 \mathrm{a}^{*}$ & $7.65 \pm 0.35 \mathrm{a}^{*}$ & $8.78 \pm 0.211^{a^{*}}$ & +++ \\
\hline Diabetic + fruits extract & $104.35 \pm 9.13 \mathrm{~b}^{*}$ & $6.11 \pm 0.64 \mathrm{~b}^{*}$ & $11.02 \pm 0.355^{b^{*}}$ & $11.70 \pm 1.79 \mathrm{~b}^{*}$ & Nil \\
\hline Diabetic + Metformin & $96.53 \pm 6.78 \mathrm{~b}^{*}$ & $5.87 \pm 0.78 \mathrm{~b}^{*}$ & $11.35 \pm 0.80 \mathrm{~b}^{*}$ & $13.56 \pm 1.98 \mathrm{~b}^{*}$ & Nil \\
\hline
\end{tabular}

Units are expressed as mg/dl for blood glucose, g/dl for hemoglobin, \% hemoglobin for HbA1c, $\mu \mathrm{U} / \mathrm{ml}$ for plasma insulin, +++ indicates more than $2 \%$ sugar. Results are expressed as mean \pm S.E.M $[n=6]$. One-way ANOVA followed by post hoc test LSD. Values are statistically significant at ${ }^{*} \mathrm{P}<0.05$. The results were compared with aControl rats, ${ }^{\mathrm{b}}$ Diabetic rats

Under physiological conditions, glycosylated hemoglobin (HbA1c) is formed by the non-enzymatic, irreversible covalent bonding of glucose with the $\mathrm{N}$ terminal Valine of hemoglobin in the circulation. During chronic hyperglycemia, the level of glycosylated hemoglobin is elevated because of increased glycation of hemoglobin due to oxidative stress induced by persistently elevated blood glucose levels. HbA1c level strongly correlates with the level of ambient glycaemia during a two to three month period and is a single, more accurate, reliable and non- manipulative measure than fasting blood glucose level. HbA1c levels are also used to predict the diabetic risk of individuals. The observed increase in the level of glycosylated hemoglobin in diabetic rats was significantly decreased upon treatment with fruits extract. This is due to improved glucose homeostasis which is evident from FBG and plasma insulin levels thereby reducing the intensity of glycation of hemoglobin in diabetic rats $[54,55]$.

Table 2 Effect of oral treatment of immature palm fruits extract on the levels of total protein, blood urea, serum uric acid and serum creatinine in experimental groups of rats.

\begin{tabular}{|l|l|l|l|l|}
\hline Groups & $\begin{array}{l}\text { Total } \\
\text { protein } \mathbf{( g / d l )}\end{array}$ & $\begin{array}{l}\text { Blood } \\
\text { urea }(\mathbf{m g} / \mathbf{d l})\end{array}$ & $\begin{array}{l}\text { Serum uric acid } \\
\mathbf{( m g / d l )}\end{array}$ & $\begin{array}{l}\text { Serum creatinine } \\
\mathbf{( m g} / \mathbf{d l})\end{array}$ \\
\hline Control & $7.56 \pm 0.47$ & $22.70 \pm 1.19$ & $2.46 \pm 0.35$ & $0.46 \pm 0.05$ \\
\hline Diabetic & $5.45 \pm 0.65 \mathrm{a}^{*}$ & $43.86 \pm 4.46 \mathrm{a}^{*}$ & $4.78 \pm 0.75 \mathrm{a}^{*}$ & $1.98 \pm 0.65 \mathrm{a}^{*}$ \\
\hline Diabetic + palm fruits extract & $6.56 \pm 0.70 \mathrm{~b}^{*}$ & $27.65 \pm 0.95 \mathrm{~b}^{*}$ & $2.45 \pm 0.75 \mathrm{~b}^{*}$ & $0.89 \pm 0.06 \mathrm{~b}^{*}$ \\
\hline Diabetic + Metformin & $6.60 \pm 0.89 \mathrm{~b}^{*}$ & $29.50 \pm 1.89 \mathrm{~b}^{*}$ & $2.12 \pm 0.12 \mathrm{~b}^{*}$ & $0.52 \pm 0.07 \mathrm{~b}^{*}$ \\
\hline
\end{tabular}

Units: $\mathrm{g} / \mathrm{dl}$ for plasma protein, $\mathrm{mg} / \mathrm{dl}$ for blood urea, serum uric acid and serum creatinine. Results are expressed as mean \pm S.E.M [n=6]. One-way ANOVA followed by post hoc test LSD. Values are statistically significant at @ $\mathrm{P}<0.05 ; \# \mathrm{P}<0.01 ;{ }^{*} \mathrm{P}<0.001$. The results were compared with aControl rats, bDiabetic rats, cDiabetic rats treated with Metformin.

Table 2 depicts the plasma protein, blood urea, serum uric acid and creatinine levels in control and experimental groups of rats. Hyperglycemia induces protein catabolism and elevation in the serum levels of urea, uric acid and creatinine 
which are considered as significant biochemical indices of renal dysfunction. Urea is the main end product of protein catabolism in the body. The antidiabetic property of fruits extract may account for the observed increase in the levels of plasma proteins. The improvement in body weight gain in diabetic rats treated with the fruits extract indicates the improved nitrogen balance.

During the diabetic conditions, the prominent deprivation of both hepatic as well as plasma proteins leads to the excessive accumulation of urea in the systemic circulation than its excretion. In diabetes, due to the elevated levels of glucose, damages occur in tissues like kidney causing impairment in renal function resulting in the accumulation of nitrogenous wastes in circulation [56]. This, in turn, elevates the levels of urea and creatinine in the blood which acts as biochemical diagnostic markers for assessing kidney function. An increase in creatinine levels usually occurs simultaneously with an increase in blood urea nitrogen. Serum creatinine concentration is often used as a variable not only to assess impairment of kidney function but also as a clinical endpoint to detect treatment related toxic effects of compounds on the kidney in experimental animals. The administration of immature fruits extract and metformin to diabetic rats normalized the blood urea, uric acid and creatinine levels indicating the recovered renal function, which is due to improved glycemic control. The increased levels of urea, uric acid and creatinine and reduced levels of plasma protein in diabetic rats were significantly improved in immature palm fruits treated diabetic rats.

The HOMA-IR value calculated for the control and experimental groups of rats is presented in Figure 3. HFD-fed low dose STZ induced diabetic rats showed a significant elevation of HOMA-IR values indicating the existence of insulin resistance. Oral administration of immature palm fruits improves insulin sensitivity, which is evident from the results of fasting blood glucose, plasma insulin and HOMA-IR and the efficacy was comparable with the metformin-treated diabetic group of rats. The homeostasis model assessment of insulin resistance (HOMA-IR), originally developed by Matthews et al. (1985) [24] has been extensively used for the assessment of insulin resistance. Insulin resistance is the primary metabolic disorder associated with obesity and appears to be the primary mediator of metabolic syndromes and type 2 diabetes mellitus [57].

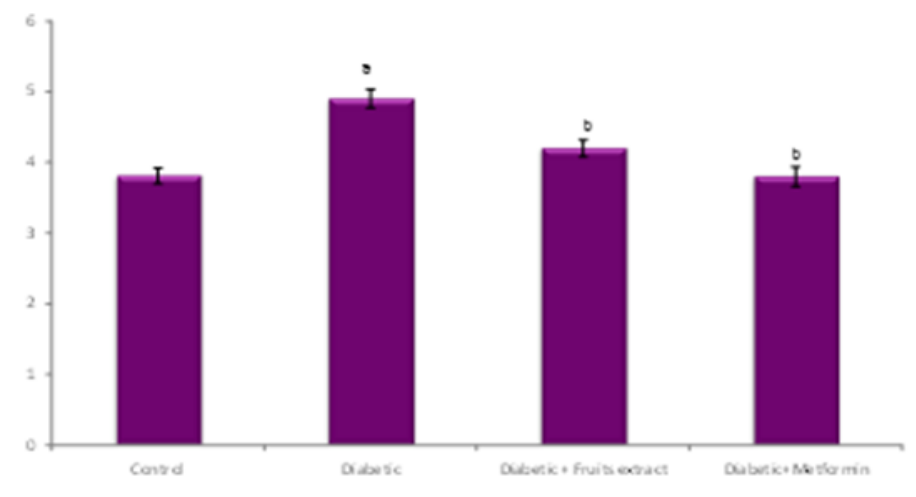

Results are exrressed as me an \pm S EM $[n=6]$, One-way ANOVh follbwed by post hoc test LSD was done Whes are statistically significart at $\mathrm{p}<005$. The resuls were campared to controlnts and campared to dibetic rats.

Figure 3 Effect of imumature palm fruits extract treatment on HOMA-IR

The activities of AST, ALT and ALP in the serum of control and experimental groups of rats are depicted in table 3. One of the most sensitive and dramatic indicators of hepatocyte injury is the release of cytosolic enzymes, such as AST and ALT in the circulation. The enzyme ALP is located in the plasma membrane and will be released into the circulation during membrane damage [58]. Liver ALP is mobilized most rapidly into the blood and its levels in plasma may increase at early periods of liver damage. In addition, the soluble enzymes ALT and AST are released when the injury involves organelles such as mitochondria [59]. Several researchers reported that the elevated activities of AST, ALT and ALP were indicative of extensive cellular damage and loss of the functional integrity of the cell membranes [60, 61]. Increase in the levels of ALP in diabetes may be a result of leaking out from the tissue into the blood stream as a result of the adverse effect of STZ in the liver [62]. The increased activities of hepatic marker enzymes AST, ALT and ALP in diabetic rats were significantly reduced upon treatment with immature palm fruits as well as treated with metformin. The elevated activities of these physiological enzymes were restored to near normal levels in fruits extract as well as metformin treated diabetic rats. 
Table 3 The activities of Aspartate transaminase, Alanine transaminase and Alkaline phosphataseinthe control and experimental groups ofrats

\begin{tabular}{|l|l|l|l|}
\hline Groups & AST & ALT & ALP \\
\hline Control & $11.16 \pm 1.25$ & $18.09 \pm 1.47$ & $0.18 \pm 0.011$ \\
\hline Diabetic & $26.29 \pm 3.08 \mathrm{a}^{*}$ & $32.78 \pm 6.48 \mathrm{a}^{*}$ & $0.67 \pm 0.080 \mathrm{a}^{*}$ \\
\hline Diabetic + palm fruits extract & $14.64 \pm 2.42 \mathrm{~b}^{*}$ & $23.82 \pm 3.66 \mathrm{~b}^{*}$ & $0.27 \pm 0.035 \mathrm{~b}^{*}$ \\
\hline Diabetic + Metformin & $13.03 \pm 4.39 \mathrm{~b}^{*}$ & $21.31 \pm 4.07 \mathrm{~b}^{*}$ & $0.21 \pm 0.039 \mathrm{~b}^{*}$ \\
\hline
\end{tabular}

Enzyme activities are expressed as: For AST and ALT - $\mu$ moles of pyruvate $/ \mathrm{min} / \mathrm{mg}$ of protein; ALP - $\mu$ moles of phenol liberated/min/mg of protein. Results are expressed as mean \pm S.D. [n=6]. One-way ANOVA followed by post hoc test LSD. The results were compared with a Control; ${ }^{b}$ Diabetic control. Values are statistically significant at ${ }^{*} \mathrm{p}<0.05$.

Liver plays a major role in the maintenance of glucose homeostasis through the regulation of hepatic glycogenolysis, gluconeogenesis and decreased utilization of glucose [63]. The dysregulation of these metabolic processes forms the fundamental factors contributing to a pathological condition termed as chronic hyperglycemia in diabetes mellitus [64]. The activities of hexokinase, pyruvate kinase and lactate dehydrogenase in the hepatic tissues of control and experimental groups of rats were presented in Table 4. The optimal activity of these glycolytic enzymes is considered as essential for the generation of energy in the form of ATP molecules through the oxidation of glucose. The activity of both hexokinase and pyruvate kinase was found to be significantly decreased in the liver tissue of experimental diabetic rats. Oral administration of immature palm fruits altered the activities of these enzymes to physiological levels. On the other hand, the activity of lactate dehydrogenase in the hepatic tissue of the diabetic group of rats was significantly elevated when compared to the control group of rats. The elevated activity of lactate dehydrogenase in diabetic rats was significantly restored back to near normal upon oral treatment with immature palm fruits.

Hexokinase (HK) is the rate-limiting glycolytic enzyme that converts glucose to glucose-6-phosphate. Experimental and clinical reports on animal models and in vitro studies demonstrated that the activity of hexokinase in hepatocytes exerts a strong correlation on the utilization of glucose and glycogen synthesis. Insulin administration rapidly restores the activity of hexokinase in hepatic tissues [65]. The observed decrease in the activity of hexokinase in experimental type 2 diabetic rats may be due to insulin resistance coupled with insufficiency.

Table 4 Effect of oral administration of immature palm fruits extract on the activities of hexokinase, pyruvate kinase and lactate dehydrogenase in the liver tissues of experimental groups of rats after 30 days of treatment.

\begin{tabular}{|l|l|l|l|}
\hline Groups & Hexokinase & Pyruvate kinase & Lactate Dehydrogenase \\
\hline Control & $255.56 \pm 17.82$ & $214.16 \pm 18.44$ & $220.22 \pm 19.87$ \\
\hline Diabetic & $136.12 \pm 11.33^{\mathrm{a}^{*}}$ & $125.32 \pm 13.25^{\mathrm{a}^{*}}$ & $480.87 \pm 31.45^{\mathrm{a}^{*}}$ \\
\hline Diabetic + palm fruits extract & $205.81 \pm 17.45^{\mathrm{b}^{*}}$ & $186.58 \pm 19.42^{\mathrm{b}^{*}}$ & $265.01 \pm 23.22^{\mathrm{b}^{*}}$ \\
\hline Diabetic + metformin & $220.37 \pm 16.51 \mathrm{~b}^{*}$ & $193.35 \pm 17.04 \mathrm{~b}^{*}$ & $246.15 \pm 25.76^{\mathrm{b}^{*}}$ \\
\hline
\end{tabular}

Units are expressed as: $\mu$ moles of glucose-6-phosphate formed/h/mg of protein for hexokinase, $\mathrm{mU} / \mathrm{mg}$ of protein for pyruvate kinase, $\mu$ moles of pyruvate formed $/ \mathrm{h} / \mathrm{mg}$ of protein for lactate dehydrogenase. Values are given as mean \pm S.D for six rats in each group. One-way ANOVA followed by post hoc test LSD. Statistical significance was compared within the groups as follows: a Control rats; ${ }^{b}$ Diabetic control rats; Values are statistically significant at ${ }^{*} \mathrm{p}<0.05$.

Pyruvate kinase (PK) is a universally expressed enzyme that catalyses the conversion of phosphoenol pyruvate to pyruvate with the release of ATP. The reduction in PK levels in diabetic conditions alters glucose metabolism and ATP production, which might be promptly responsible for the reduced rate of glycolysis and augmented gluconeogenesis [66]. Oral administration of immature palm fruits to the diabetic rats resulted in an increase in the PK activity.

Lactate dehydrogenase (LDH) is a terminal glycolytic enzyme which catalyses the interconversion of pyruvate to lactate to yield energy under anaerobic conditions [67]. Elevated levels of LDH are observed in experimental diabetic animals which are attributed to impaired glucose-stimulated insulin secretion [68]. Thus, the normal glucose metabolism and insulin secretion in the $\beta$-cells are disturbed with the increased activity of LDH. Upon treatment with immature palm fruits to diabetic rats showed a significant reduction in the LDH activity, probably due to the regulation of NAD+/NADH ratio by the oxidation of glucose. 
Glucose-6-phosphatase, a gluconeogenic enzyme that catalyzes the dephosphorylation of glucose-6- phosphate to glucose [69] and Fructose-1, 6- bisphosphatase is another gluconeogenic enzyme that catalyzes the dephosphorylation of fructose-1,6- bisphosphate to fructose-6-phosphate serves as a place for the regulation of gluconeogenesis [70]. The activities of these enzymes were significantly increased in diabetic rats when compared to normal control rats whereas the activities of glucose-6-phosphate dehydrogenase were significantly decreased were depicted in table 5. Upon treatment with the immature palm fruits, the activities of glucose-6-phosphatase, fructose-1, 6-diphosphatase were found to be decreased. This might be due to increased insulin secretion and sensitivity, which is responsible for the suppression of the activities of gluconeogenic enzymes. The glycogen content in the liver and the activities of glycogen synthase and glycogen phosphorylase were shown in table 6.

Table 5 Activities of glucose-6-phosphatase, fructose-1, 6-bisphosphatase and glucose-6-phosphate dehydrogenase in liver tissues of control and experimental groups of rats

\begin{tabular}{|l|l|l|l|}
\hline Groups & Glucose-6-phosphatase & $\begin{array}{l}\text { Fructose-1,6- } \\
\text { bisphosphatase }\end{array}$ & $\begin{array}{l}\text { Glucose-6-phosphate } \\
\text { dehydrogenase }\end{array}$ \\
\hline Control & $1042.94 \pm 120.61$ & $464.85 \pm 25.33$ & $507.11 \pm 21.82$ \\
\hline Diabetic & $1993.71 \pm 157.08^{\mathrm{a}^{*}}$ & $819.70 \pm 51.61^{\mathrm{a}^{*}}$ & $258.85 \pm 16.68^{\mathrm{a}^{*}}$ \\
\hline Diabetic + palm fruits extract & $1241.43 \pm 115.45^{\mathrm{b}^{*}}$ & $512.42 \pm 24.61^{\mathrm{b}^{*}}$ & $378.59 \pm 18.02^{\mathrm{b}^{*}}$ \\
\hline Diabetic + metformin & $1159.08 \pm 112.10^{\mathrm{b}^{*}}$ & $504.01 \pm 30.28^{\mathrm{b}^{*}}$ & $420.88 \pm 19.03^{\mathrm{b}^{*}}$ \\
\hline
\end{tabular}

Units are expressed as: $\mu$ moles of Pi liberated/h/mg of protein for glucose-6-phosphatase and fructose-1, 6-bisphosphatase and $\mu \mathrm{moles}$ of $\mathrm{NADPH} / \mathrm{min} / \mathrm{mg}$ of protein for glucose-6-phosphate dehydrogenase. Values are given as mean \pm S.D for six rats in each group. One-way ANOVA followed by post hoc test LSD. Statistical significance was compared within the groups as follows: a Control rats; biabetic control rats; Values are statistically significant at* $\mathrm{p}<0.05$.

Table 6 The Levels of glycogen content and the activities of glycogen synthase and glycogen phosphorylase in liver tissues of control and experimental groups of rats.

\begin{tabular}{|l|l|l|l|}
\hline Groups & Glycogen & Glycogen synthase & Glycogen phosphorylase \\
\hline Control & $61.56 \pm 3.52$ & $795.98 \pm 41.62$ & $610.76 \pm 34.70$ \\
\hline Diabetic & $23.09 \pm 4.29^{\mathrm{a}^{*}}$ & $513.30 \pm 28.45^{\mathrm{a}^{*}}$ & $869.53 \pm 53.11^{\mathrm{a}^{*}}$ \\
\hline Diabetic + palm fruits extract & $48.59 \pm 4.45^{\mathrm{b}^{*}}$ & $717.23 \pm 30.21^{\mathrm{b}^{*}}$ & $652.18 \pm 30.56^{\mathrm{b}^{*}}$ \\
\hline Diabetic + metformin & $54.31 \pm 3.02^{\mathrm{b}^{*}}$ & $726.89 \pm 50.32^{\mathrm{b}^{*}}$ & $672.53 \pm 35.89 \mathrm{~b}^{*}$ \\
\hline
\end{tabular}

Units are expressed as: $\mathrm{mg} / \mathrm{g}$ wet tissue for glycogen, $\mu$ moles of UDP formed/h/mg protein for glycogen synthase and $\mu \mathrm{moles}$ Pi liberated/h/mg protein for glycogen phosphorylase. Values are given as mean \pm S.D for six rats in each group. One-way ANOVA followed by post hoc test LSD. Statistical significance was compared within the groups as follows: ${ }^{a}$ Control rats; ${ }^{b}$ Diabetic control rats; Values are statistically significant at* $p$ $<0.05$.

The decreased glycogen content observed in diabetic rats was improved upon treatment with fruits extract and metformin indicating the improved insulin sensitivity in the liver tissue. Glycogen is the chief intracellular storable form of glucose and its quantity in various tissues is a direct manifestation of insulin activity as insulin supports intracellular glycogen deposition by stimulating glycogen synthase and inhibiting glycogen phosphorylase [71]. Glycogen synthase is a vital enzyme, which catalyzes the transfer of glucose from UDP-glucose to glycogen. Glycogen phosphorylase is a rate-limiting enzyme of glycogenolysis and is regulated by phosphorylation and by allosteric binding of AMP, ATP, glucose-6-phosphate and glucose [72]. During diabetic conditions, the glycogen levels, glycogen synthase activity and responsiveness to insulin signaling are reduced and glycogen phosphorylase activity is significantly increased [73]

\section{Conclusion}

The present study provides scientific validation for the use of immature fruits of palmyra palm in the treatment of diabetes and its secondary complications. The observed decrease in the levels of fasting blood glucose, insulin, hemoglobin, glycosylated hemoglobin, urea, uric acid, creatinine along with the activities of enzymes involved in the toxicity and regulation of carbohydrate and glycogen metabolism evidenced the nontoxic and significant antidiabetic properties of the immature palmyra palm fruits. 


\section{Compliance with ethical standards}

\section{Disclosure of conflict of interest}

The authors declare no conflict of interest.

\section{Statement of ethical approval}

The animal experiments were designed and conducted in accordance with the current ethical norms approved by Ministry of Social Justices and Empowerment, Government of India and Institutional Animal Ethical Committee Approval (IAEC No.04/01/2014).

\section{References}

[1] American Diabetes Association. Diagnosis and classification of diabetes mellitus. Diabetes care. 2014; 37(1): 8190.

[2] P Zimmet, Kelly West Lecture. Challenges in diabetes epidemiology-from West to the Rest. Diabetes Care. 1992; 15: 232-252.

[3] JS Skyler, GL Bakris, E Bonifacio. Differentiation of diabetes by pathophysiology, natural history, and prognosis. Diabetes. 2017; 66: 241-255.

[4] P Zimmet. Diabetes epidemiology as a trigger to diabetes research. Diabetologia. 1999; 42: 499-518.

[5] F Folli, Domenico Corradi, Paolo Fanti, Alberto Davalli, Ana Paez, Andrea Giaccari, Carla Perego and Giovanna Muscogiuri. The Role of Oxidative Stress in the Pathogenesis of Type 2 Diabetes Mellitus Micro- and Macrovascular Complications: Avenues for a Mechanistic-Based Therapeutic Approach. Current Diabetes Reviews. 2011; 7: 313-324.

[6] IA Leclercq, A Da Silva Morais, B Schroyen, N Van Hul, A Geerts. Insulin resistance in hepatocytes and sinusoidal liver cells: Mechanisms and consequences. J Hepatol. 2007; 47: 142-56.

[7] SA Raptis, GD Dimitriadis. Oral hypoglycemic agents: insulin secretagogues, alpha-glucosidase inhibitors and insulin sensitizers. Exp Clin Endocrinol Diabetes. 2001; 109(2): 265-87.

[8] NR Farnsworth, O Akerele, AS Bingel, , DD Soejarto, Z Guo. Medicinal plants in therapy. Bulletin of the World Health Organization. 1985; 63: 965-981.

[9] JF Morton. Notes on Distribution, Propagation, and Products of Borassus Palms (Arecaceae). Economic Botany. 1988; 42(3): 420-441.

[10] PC Vengaiah, GN Murthy, KR Prasad, KU Kumari. Post-harvest technology of Palmyra (Borassus flabellifer L) present practises and scope. International conference on food processing by Omics group, India. 2012.

[11] Ankita Aman, Rajni Rajan, Suparna Sinha. The Palmyrah Palm (Borassus flabellifer L.): Overview of Biology, Uses, and Cultivation. Biomolecule Reports. 2018.

[12] S Arulraj, BJ Augustine. Underutilized palms. In: Peter KV. Ed. Underutilized and underexploited horticultural crops. New India Publishing Agency. 2008; 3: 415-29.

[13] VS Ramachandran, K Swarupanandan, Renuka C. A traditional irrigation system using Palmyra palm Borassus flabellifer in Kerala, India. Palms. 2004; 48: 175-81.

[14] KS Saravanya, SA Kavitha. Study on properties of Palmyra sprout. Int J Curr Res. 2017; 9:54299-54301.

[15] I Uluwaduge, AA Punya, SN Senadheera, ER Jansz. Studies onthe natural hydrophobic blinder of flabelliferins and their effect on some bioactivities. J. Natl. Sci. Found .Sri Lanka. 2005; 33: 187-191.

[16] I Uluwaduge, MI Thabrew, ER Janz. The effect of flabelliferins of palmyrah fruit pulp on intestinal glucose uptake in mice. J. Natl. Sci. Found. Sri Lanka. 2006; 34: 37-41.

[17] K Renuka, V Roshana Devi, SP Subramanian. Phytochemical screening and evaluation of in vitro Antioxidant potential of immature Palmyra palm (Borassus Flabellifer Linn.) fruits. Int J Pharm Pharm Sci. 2018; 10(8): 77 83. 
[18] K Renuka, C Sharmila, SP Subramanian. Evaluation of Antimicrobial activity of immature Palmyra palm (Borassus flabellifer linn.) fruits. Int. J. Pharm. Sci. Rev. Res. 2019; 55(1): 50-57.

[19] JB Harbone. Phytochemical Methods. London: Chapman and Hall. 1998; 117-9.

[20] CK Kokate, AP Purohit, SB Gokhale. Drug's containing glycosides, drugs containing tannins, lipids and protein alkaloids. Text Book of Pharmacognosy: Carbohydrate and Derived Products. 7th ed. India: Nitrali Prakashan. $2001 ; 133-523$.

[21] OECD. Guideline Number 423 for the Testing of Chemicals: Revised Draft Guideline 423 (Acute Oral Toxicity). Paris. France: OECD. 2000.

[22] Pradeep Goyal, Anil Agarwal, Lakshminarasimhaiah, GK Singh. Hypoglycemic Activity of Inflorescence of Borassus flabellifer Extracts on Blood Glucose Levels of Streptozocin-Induced Diabetic Rats. Journal of Pharmacy Research. 2014; 8(11): 1738-1742.

[23] RK Suman, IR Mohanty, MK Borde, U Maheshwari, YA Deshmukh. Development of an experimental model of diabetes co-existing with metabolic syndrome in rats. Advances in Pharmacological Sciences. 2016; 1-11.

[24] D Matthews, J Hosker, A Rudenski, B Naylor, D Treacher, R Turner. Homeostasis model assessment: insulin resistance and beta cell function from fasting plasma glucose and insulin concentrations in man. Diabetologia. 1985; 28: 412-419.

[25] P Trinder. Determination of blood glucose using an oxidaseperoxidase system with a non-carcinogenic chromogen. J Clin Pathol. 1969; 22: 158-161.

[26] DL Drabkin, JM Austin. Spectrophotometric constants for common hemoglobin derivatives in human, dog and rabbit blood. J Biol Chem. 1932; 98: 719-733.

[27] SS Nayak, TN Pattabiraman. A new colorimetric method for the estimation of glycosylated hemoglobin. Clin Chem Acta. 1981; 109: 267-274.

[28] OH Lowry, NJ Rosebrough, , AL Farr, RJ Randall. Protein measurement with the Folin phenol reagent. J Biol Chem. 1951; 193: 265-275.

[29] S Natelson, ML Scott, E Begga. A rapid method for the estimation of urea in biological fluids by means of the reaction between diacetyl and urea. Am J Clin Pathol. 1951; 21: 275- 281.

[30] J Brod, JH Sirota. The renal clearance of endogenous "creatinine" in man. J Clin Invest. 1948; 27: 645-654.

[31] WI Caraway. Uric acid. In: Standard methods of clinical chemistry. (Ed.) Seligson D. Vol.4, Academic Press, New York. 1963; 239-247.

[32] J King. The transaminases: alanine and aspartate transaminases. In: Practical Clinical Enzymology (ed.) D Van, Nostrand Co., London. 1965a; 363-395.

[33] J King. The hydrolases-acid and alkaline phosphatases. In: Practical clinical enzymology. (Ed.) Van D. Nostrand Co, London.1965b; 199-208.

[34] N Brandstrup, JE Kirk, C Bruni. The hexokinase and phosphoglucoisomerase activities of aortic and pulmonary artery tissue in individuals of various ages. J Gerontol. 1957; 12: 166-171.

[35] CI Pogson, RM Denton. Effect of alloxan diabetes, starvation and refeeding on glycolytic kinase activities in rat epididymal adipose tissue. Nature. 1967; 216: 156-157.

[36] H Koide, T Oda. Pathological occurrence of glucose-6-phosphatase in serum in liver diseases. Clin ChimActa. 1959; 4: 554-561.

[37] JM Gancedo, C Gancedo. Fructose-1, 6 diphosphatase, phosphofructokinase and glucose-6-phosphate dehydrogenase from fermenting and non-fermenting yeasts. Arch Mikrobiol. 1971; 76:132-138.

[38] HA Ells, HN Kirkman. A colorimetric method for assay of erythrocytic glucose- 6-phosphate dehydrogenase. Proc Soc Exp Biol Med. 1967; 106: 607-609.

[39] LF Leloir, SH Goldemberg. Glycogen synthetase from rat liver: (Glucose)n+ (UDPG) $\rightarrow$ (Glucose)n+1+UDP. In: Colowick, S.P., Kalpan, N.O. (Eds.), Methods in Enzymology. Academic Press, New York. 1962; 145-147.

[40] M Cornblath, PJ Randle, A Parmeggiani, HE Morgan. Effects of phospholipids and anoxia on lactate production, glycogen content, and phosphorylase activity in the perfused isolated rat heart. J Biol Chem. 1963; 238: 15921597. 
[41] MA Morales, AJ Jabbagy, HR Terenizi. Mutations affecting accumulation of glycogen. Neurospora News.1973; 20: 24-25.

[42] B Singchai, K Kansane, B Chourykaew. Phytochemical screening and biological activities of Borassus flabellifer L. Asian J Pharm Clin Res. 2015; 8: 151-3.

[43] AJ Sarkodie, AS Squire, AI Kretchy. Borassus aethiopum, a potential medicinal source of antioxidants, antiinflammatory and antimicrobial agents. Herb Med. 2015; $2: 1$.

[44] S Kumar,M Pooja, K Harika, EHiawatha, G Nagabhushanamma, N Vidyavathi. In vitro antioxidant activities, total phenolics and flavonoid contents of whole plant of Hemidesmus indicus Linn. Asian J Pharm Clin. 2013; 6: 24951.

[45] D Somit, D Priyankar, CT Kumar. Quantification and correlation of the bioactive phytochemicals of Croton bonplandianum leaves of sub-Himalayan region of West Bengal. Asian J Pharm Clin Res. 2013; 6: 142-7.

[46] SK Swanston-Flat, C Day, CJ Bailey, PR Flatt. Traditional plant treatment for diabetes: Studies in normal and streptozotocin diabetic mice. Diabetologia. 1990; 33: 462-464.

[47] KG Alberti, PZ Zimmet. Definition, diagnosis and classification of diabetes mellitus and its complications. Part 1: diagnosis and classification of diabetes mellitus provisional report of a WHO consultation. Diabet Med. 1998; 15(7): 539-553.

[48] JP Sheehan. Fasting hyperglycemia: etiology, diagnosis, and treatment. Diabetes Technol Ther. 2004; 6(4): 525533.

[49] A Barthel, D Schmoll. Novel concepts in insulin regulation of hepatic gluconeogenesis. Am J Physiol Endocrinol Metab. 2003; 285(4): E685-692.

[50] DS Edgerton, S Cardin, C Pan, D Neal, B Farmer, M Converse, AD Cherrington. Effects of insulin deficiency or excess on hepatic gluconeogenic flux during glycogenolytic inhibition in the conscious dog. Diabetes. 2002; 51(11): 3151-3162.

[51] J Girard. The Inhibitory Effects of Insulin on Hepatic Glucose Production Are Both Direct and Indirect. Diabetes. 2006; 55(2): S65-S65.

[52] M Roden. Hepatic glucose production and insulin resistance. Wien Med Wochenschr. 2008; 158(19-20): 558561.

[53] R Ilouz, O Kaidanovich, D Gurwitz, H Eldar-Finkelman. Inhibition of glycogen synthase kinase-3beta by bivalent zinc ions: insight into the insulin-mimetic action of zinc. Biochem Biophys Res Commun. 2002; 295(1): 102-6.

[54] YM Luijf, J Hermanides, MJ Serlie, JB Hoekstra, MR Soeters. The added value of oral glucose tolerance testing in pre-diabetes. Curr Diabetes Rev. 2011; 7(1): 56-60.

[55] X Zhuang, X Pang, W Zhang, W Wu, J Zhao, H Yang, W Qu. Effects of zinc and manganese on advanced glycation end products (AGEs) formation and AGEs-mediated endothelial cell dysfunction. Life Sci. 2012; 90(3-4): 131-9.

[56] TP Almdal, H Vilstrup. Exogenous hyperglucagonaemia in insulin controlled diabetic rats increases urea excretion and nitrogen loss from organs. Diabetologia. 1988; 31(11): 836-41.

[57] MW Haymond. Measuring insulin resistance: a task worth doing: but how?. Pediatr Diabetes. 2003; 4: 115-118.

[58] R Sallie, JM Tredger, R Williams. Drugs and the liver. Part 1: Testing liver function. Biopharm Drug Dispos. 1991; 12(4): 251-9.

[59] S Kumar Rajagopal, P Manickam, V Periyasamy, N Namasivayam. Activity of Cassia auriculata leaf extract in rats with alcoholic liver injury. J Nutr Biochem. 2003; 14(8): 452-8.

[60] B Saraswat, PK Visen, GK Patnaik, BN Dhawan. Anticholestatic effect of picroliv, active hepatoprotective principle of Picrorhiza kurrooa, against carbon tetrachloride induced cholestasis. Indian J Exp Biol. 1993; 31(4): 316-8.

[61] MG Rajesh MS Latha. Preliminary evaluation of the antihepatotoxic activity of Kamilari, a polyherbal formulation. J Ethnopharmacol. 2004; 91(1): 99-104.

[62] FE Uboh, EO Iniobong, MB Ekong. Effect of Aqueous Extract of Psidium guajava Leaves on Liver Enzymes, Histological Integrity and Haematological Indices in Rats. Gastroenterol. Res. 2010; 3(1): 32-38.

[63] RC Nordlie, JD Foster, AJ Lange. Regulation of glucose production by the liver. Annul Rev Nutr. 1999; 19: 379406. 
[64] A Shirwaikar, A Shirwaikar, K Rajendran, IS Punitha. In vitro antioxidant studies on the benzyl tetra isoquinoline alkaloid berberine. Biol Pharm Bull. 2006; 29: 1906-1910.

[65] C Postic, M Shiota, MA Magnuson. Cell-specific roles of glucokinase in glucose homeostasis. Recent Prog Horm Res. 2001; 56: 195-217.

[66] B Chaneton, P Hillmann, L Zheng, AC Martin, OD Maddocks, A Chokkathukalam, JE Coyle, A Jankevics, FP Holding, KH Vousden, C Frezza, M O'Reilly, E Gottlieb. Serine is a natural ligand and allosteric activator of pyruvate kinase M2. Nature. 2012; 491(7424): 458-62.

[67] NC Denko. Hypoxia, HIF1 and glucose metabolism in the solid tumour. Nat Rev Cancer. 2008; 8(9): 705-13.

[68] S Rajeswarareddy, T Lavany, G Narasimhulu, K Sathyavelureddy. Effect of Pimpinellatirupatiensison Oxidative Enzymes in STZ-induced Diabetic Rat Kidney. Iran J Pharm Res. 2012; 11(1): 277-86.

[69] AR Saltiel, CR Kahn. Insulin signalling and the regulation of glucose and lipid metabolism. Nature. 2001; 414(6865): 799-806.

[70] G Mahendran, M Manoj, E Murugesh, R Sathish Kumar, P Shanmughavel, KJ Rajendra Prasad, V Narmatha Bai. In vivo anti-diabetic, antioxidant and molecular docking studies of 1, 2, 8-trihydroxy-6-methoxy xanthone and 1, 2dihydroxy-6- methoxyxanthone-8-0-ß-D-xylopyranosyl isolated from Swertia corymbosa. Phytomedicine. 2014; 21(11): 1237-48.

[71] RE Flückiger-Isler, P Walter. Stimulation of rat liver glycogen synthesis by the adenosine kinase inhibitor 5iodotubercidin. Biochem J. 1993; 292(1): 85-91.

[72] ML Parolin, LL Spriet, E Hultman, MG Hollidge-Horvat, NL Jones, GJ Heigenhauser. Regulation of glycogen phosphorylase and PDH during exercise in human skeletal muscle during hypoxia. Am J Physiol Endocrinol Metab. 2000; 278(3): E522-34.

[73] JC Ferrer, C Favre, RR Gomis, JM Fernández-Novell, M García-Rocha, N de la Iglesia, E. Cid, JJ Guinovart. Control of glycogen deposition. FEBS Lett 2003; 546(1): 127-32. 